\title{
Effect of microRNA-145 to prevent vein graft disease in rabbits by regulation of smooth muscle cell phenotype
}

\author{
Motoaki Ohnaka, MD, ${ }^{\mathrm{a}}$ Akira Marui, MD, PhD, ${ }^{\mathrm{a}}$ Kenichi Yamahara, MD, PhD, ${ }^{\mathrm{b}}$ Kenji Minakata, MD, PhD, ${ }^{\mathrm{a}}$ \\ Kazuhiro Yamazaki, MD, PhD, ${ }^{\mathrm{a}}$ Motoyuki Kumagai, MD, ${ }^{\mathrm{a}}$ Hidetoshi Masumoto, MD, PhD, ${ }^{\mathrm{a}}$ \\ Shiro Tanaka, $\mathrm{PhD},{ }^{\mathrm{c}}$ Tadashi Ikeda, $\mathrm{MD}, \mathrm{PhD},{ }^{\mathrm{a}}$ and Ryuzo Sakata, $\mathrm{MD}, \mathrm{PhD}^{\mathrm{a}}$
}

\begin{abstract}
Objective: Because microRNA-145 (miR-145) is a specific mediator in the regulation of the proliferation and differentiation of smooth muscle cells, we investigated the effect of miR-145 on the intimal hyperplasia in the rabbit model of vein graft disease using electroporation-mediated gene transfer.
\end{abstract}

\begin{abstract}
Methods: The right jugular vein of male Japanese white rabbits was harvested and transduced with miR-145encoding plasmids using an electroporator and then interposed in the carotid artery. At 2 or 4 weeks postoperatively, the venous graft was explanted, and the intimal thickness and intima/media area ratio were evaluated. Furthermore, 3 days after implantation, the myocardin and serum response factors were measured using realtime polymerase chain reaction. At 2 weeks after implantation, immunohistochemical investigations using mature smooth muscle markers, myosin heavy chain smooth muscle-1 and -2, and proliferation marker Ki-67 were performed.
\end{abstract}

Results: MiR-145 transduction significantly reduced the neointimal thickness at both 2 and 4 weeks ( 2 weeks, $52.1 \pm 15.7$ vs $113.2 \pm 26.9 \mu \mathrm{m}, P<.05, \mathrm{n}=6$; 4 weeks, $42.4 \pm 4.8$ vs $136.5 \pm 38.3 \mu \mathrm{m}, P<.05, \mathrm{n}=8$ ), and it also significantly reduced the intima/media area ratio at 4 weeks $(0.22 \pm 0.04$ vs $1.13 \pm 0.23, P<.01, \mathrm{n}=8)$. Additionally, it upregulated the mRNA expression level of myocardin compared with that in the grafts that did not receive gene transfer. Smooth muscle-2 and Ki-67 expression revealed that miR-145 transduced grafts contained more smooth muscle-2-positive mature smooth muscle cells and fewer Ki-67-positive proliferating cells.

Conclusions: Nonviral transduction of miR-145 into the bypass graft could be a novel option for preventing intimal hyperplasia in vein graft disease. (J Thorac Cardiovasc Surg 2014;148:676-82)

Supplemental material is available online.

The autologous vein graft has been widely used for revascularization in coronary artery bypass grafting since its introduction in $1969 .{ }^{1}$ Nevertheless, owing to accelerated atherosclerosis, these vein grafts have had a lower patency rate than those of other arterial grafts. ${ }^{2}$ Thrombotic occlusion followed by intimal hyperplasia is the major cause of vein graft disease, and vascular smooth muscle cell

From the Department of Cardiovascular Surgery, ${ }^{\text {a }}$ Kyoto University Graduate School of Medicine, Kyoto, Japan; Department of Regenerative Medicine and Tissue Engineering, ${ }^{\mathrm{b}}$ National Cerebral and Cardiovascular Center, Osaka, Japan; and Department of Pharmacoepidemiology, ${ }^{\mathrm{c}}$ Kyoto University Graduate School of Medicine and Public Health, Kyoto, Japan.

This work was supported by a grant for Scientific Research (B) (grant 22390265) from the Japanese Ministry of Education, Culture, Sports, Science, and Technology.

Disclosures: Authors have nothing to disclose with regard to commercial support.

Received for publication Sept 5, 2013; revisions received Oct 27, 2013; accepted for publication Nov 15, 2013; available ahead of print Feb 6, 2014.

Address for reprints: Akira Marui, MD, $\mathrm{PhD}$, Department of Cardiovascular Surgery,

Kyoto University Graduate School of Medicine, 54 Kawara-cho, Shogoin, Sakyo-ku,

Kyoto 606-8507, Japan (E-mail: marui@kuhp.kyoto-u.ac.jp).

$0022-5223 / \$ 36.00$

Copyright (c) 2014 by The American Association for Thoracic Surgery

http://dx.doi.org/10.1016/j.jtcvs.2013.11.054
(SMC) proliferation and migration into the intima are the key mechanisms in this process. Chamley-Campbell and colleagues $^{3}$ first described the phenotypic modulation of SMCs from the contractile state to the synthetic state. Phenotypic alternations of vascular SMCs have been identified as playing an important role in the response to atherosclerosis, arterial injury, and bypass vein grafting. ${ }^{4-10} \mathrm{We}$ have previously demonstrated that C-type natriuretic peptide suppressed neointimal lesion formation in the arterialized rabbit vein graft model using adenovirusmediated gene transfer. ${ }^{11}$ We also reported that overexpression of C-type natriuretic peptide in SMCs induced growth inhibition of proliferating SMCs, with alteration of the phenotype from the synthetic state to the contractile state. ${ }^{12}$

MicroRNAs are a new class of small ( $\sim 22$ nucleotides) noncoding RNA. In most cases, microRNAs negatively regulate expression of protein-coding genes by promoting degradation or suppressing translation of target mRNAs and modulating various biologic functions. ${ }^{13}$ Currently, microRNAs are under investigation as a new modality of gene therapy for ischemic heart disease and vascular diseases. ${ }^{14}$ Recent studies have reported that microRNA-145 (miR145 ) is a specific mediator in the regulation of proliferation, differentiation, and phenotype of SMCs and is necessary for maintaining a differentiated SMC phenotype. ${ }^{4-7}$ 


\section{Abbreviations and Acronyms \\ $\mathrm{GFP}=$ green fluorescent protein \\ $\operatorname{miR}-145=$ microRNA-145 \\ SMC $=$ smooth muscle cell \\ SM-1 = smooth muscle-1 \\ SM-2 = smooth muscle-2 \\ $\mathrm{SRF}=$ serum response factor}

In recent years, electroporation-mediated gene transfer has emerged in the in vivo study for future clinical applications designed at overcoming virus-related problems. ${ }^{15}$ Therefore, in the present study, we investigated the effect of miR-145 on intimal hyperplasia in the rabbit model of vein graft disease using electroporation-mediated gene transfer.

\section{METHODS}

\section{Animals}

A total of 50 male Japanese white rabbits weighing 2.5 to $3.5 \mathrm{~kg}$ were used. The rabbits were maintained with a 12-hour light/dark schedule and fed a regular rabbit chow diet. The rabbits were randomly divided into 2 groups: a control group $(\mathrm{n}=25)$ without electroporation-mediated gene transfer and a miR-145 electroporation group $(n=25)$. Three days after the operation, 4 rabbits were killed for green fluorescent protein (GFP) immunostaining and 5 rabbits for reverse transcriptase polymerase chain reaction (PCR) study in each group. Another 8 rabbits from each group were killed at 2 and 4 weeks after the initial histologic examination. The Kyoto University animal experiment review board approved the present experiment (approval reference no. MedKyo 12185). All the rabbits were used in accordance with the guidelines for animal experiments of Kyoto University, which conforms to the law of the "Guide for the Care and Use of Laboratory Animals" in Japan.

\section{Plasmid Preparation}

Expression vector for human miR-145 (pMIW-cGFP-miR-145) was obtained from B-Bridge Co, Ltd (Tokyo, Japan). In the construction of this vector, a GFP expression site was included to confirm successful gene transduction after electroporation (Appendix Figure 1).

\section{Electric Pulse Delivery for Gene Electroporation}

Electric pulses were delivered using an electric pulse generator (Super Electroporator NEPA21, Nepa Gene Co, Ltd, Chiba, Japan). Figure 1, A, shows a schematic representation of the electroporation device. Freshly isolated vein grafts were suspended in balanced salt saline $(140 \mathrm{mM} \mathrm{NaCl}, 5.4$ $\mathrm{mM} \mathrm{KCl}$, and $10 \mathrm{mM} \mathrm{HCL}, \mathrm{pH} 7.6$ ) with $500 \mu \mathrm{g} / \mathrm{mL}$ of vector and placed in an electrode chamber, as reported previously. ${ }^{16,17}$ First, to confirm the validity of the electroporation method, we performed a preliminary in vitro study using the DsRed expression vector in which several electric pulse parameters were tested ("poring pulse": voltage 25, 50, and $75 \mathrm{~V}$; pulse duration, 5 and $10 \mathrm{~ms}$; interval, 95 and $90 \mathrm{~ms}$; number of pulses, 2, 4, and 6; "transfer pulse": voltage, $10 \mathrm{~V}$; pulse duration, 5 and $10 \mathrm{~ms}$; interval, 95 and $90 \mathrm{~ms}$; number of pulses, 5 and 10; Appendix Table 1). After electroporation, the grafts were suspended in $\alpha$-minimal essential medium (Invitrogen, Carlsbad, Calif) supplemented with $10 \%$ fetal bovine serum (Invitrogen) and 1\% penicillin/streptomycin (Invitrogen), and cultured in standard plastic dishes for 2 days. The grafts were observed using fluorescence microscopy and by immunostaining using monoclonal antibodies against DsRed. Second, to decide on the optimal conditions for electroporation, several electric pulse parameters were tested using the miR-145 expression vector with a GFP expression site. These variables were chosen on the basis of the results from our experiment using the DsRed expression vector and earlier well-documented reports that used the electroporation method. ${ }^{16-18}$ Finally, 2 electric poring pulses ( $25 \mathrm{~V}, 5-\mathrm{ms}$ duration, $95-\mathrm{ms}$ interval) followed by 8 transfer pulses ( $10 \mathrm{~V}, 5$-ms duration, 95-ms interval) were adopted according to the results of both DsRed and GFP apparent expression shown in Appendix Figure 2 and Figure 1, $C$.

\section{Arterialized Rabbit Vein Graft Model}

The operative procedure was performed under aseptic conditions. Anesthesia was achieved by administration of pentobarbital sodium $(25 \mathrm{mg} / \mathrm{kg}$ intravenously) and lidocaine hydrochloride $(50 \mathrm{mg} / \mathrm{kg}$ subcutaneously). After a longitudinal neck incision, a 15- to 20 -mm segment of the right jugular vein was exposed, and all the branches of the vein were ligated. A $2 \mathrm{~F}$ Fogarty balloon catheter was inserted. After the balloon was inflated with $0.2 \mathrm{~mL}$ of air, the intima of the vein was denuded by 3 passages of the catheter. The vein was removed and kept moistened in heparinized saline (10 $\mathrm{IU} / \mathrm{mL}$ ) at room temperature. After the rabbits had been given intravenous heparin (200 IU/kg), a 15- to 20-mm segment of the common carotid artery was meticulously isolated with vascular forceps and then removed. The prepared vein graft was interposed in the carotid artery in a reversed end-to-end fashion. Anastomoses were created with 10-0 nylon continuous suture under $\times 10$ magnification using an operative microscope. To facilitate the intimal hyperplasia, the internal carotid artery and one of the branches of the external carotid artery were ligated with 6-0 silk suture. The wound was closed layer to layer. Cefazolin sodium was given intravenously as a prophylactic measure.

\section{Intimal Hyperplasia Assessment}

At 2 or 4 weeks after the operation, the vein grafts were harvested under general and local anesthesia, and the rabbits were killed by an overdose of pentobarbital sodium. The harvested vein grafts were fixed with $10 \%$ phosphate-buffered formalin at a pressure of $100 \mathrm{~mm} \mathrm{Hg}$ for 20 minutes. The perfused vein graft was immersed in the same fixative overnight and subjected to histologic examination. At least 4 sections were obtained from each vein graft and stained with both hematoxylin and eosin and elastica van Gieson. The neointima was defined as the area from the inner surface to the internal elastic lamina. The cross-sectional intimal thickness was measured at 6 randomly selected views per section. The average of the 6 values was used to represent intimal hyperplasia. The crosssectional intima/media area ratio was also calculated.

\section{Immunohistochemical Staining}

At 3 days postoperatively, the vein grafts were explanted, and GFP immunostaining was performed to confirm the gene transduction of miR-145 using the electroporation method. At 2 weeks postoperatively, the vein grafts were explanted and analyzed by immunostaining using monoclonal antibodies against myosin heavy chain smooth muscle-1 (SM-1) and smooth muscle-2 (SM-2; Yamasa Corp, Tokyo, Japan). SM-1 is constitutively expressed in all types of adult SMCs, but SM-2 exists only in mature differentiated SMCs. ${ }^{8-10}$ Additionally, immunohistochemical staining with Ki-67 monoclonal antibody (DAKO Cytomation, Glostrup, Denmark) was performed to identify the proliferative cells in the neointima. The quantitative analysis was performed as follows. The total and Ki-67-positive cells were counted in 8 randomly selected high-power fields (original magnification, $\times 400)$ per section, and the number of Ki-67-positive cells/total number of cells counted was defined as the Ki- 67 index.

\section{Quantitative Real-Time PCR Analysis}

At 3 days after implantation, the vein grafts were explanted and preserved immediately in liquid nitrogen. Total RNA was then extracted from the vein using the RNeasy Mini Kit (Qiagen, Venlo, The Netherlands) and reverse transcribed with the SuperScript III First-Strand Synthesis 


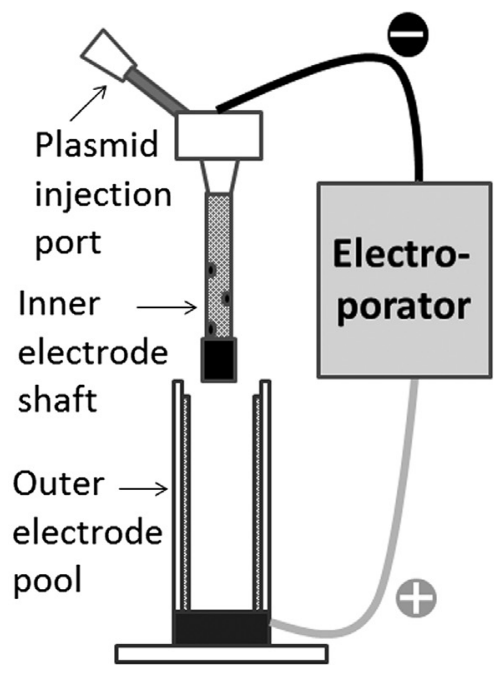

A

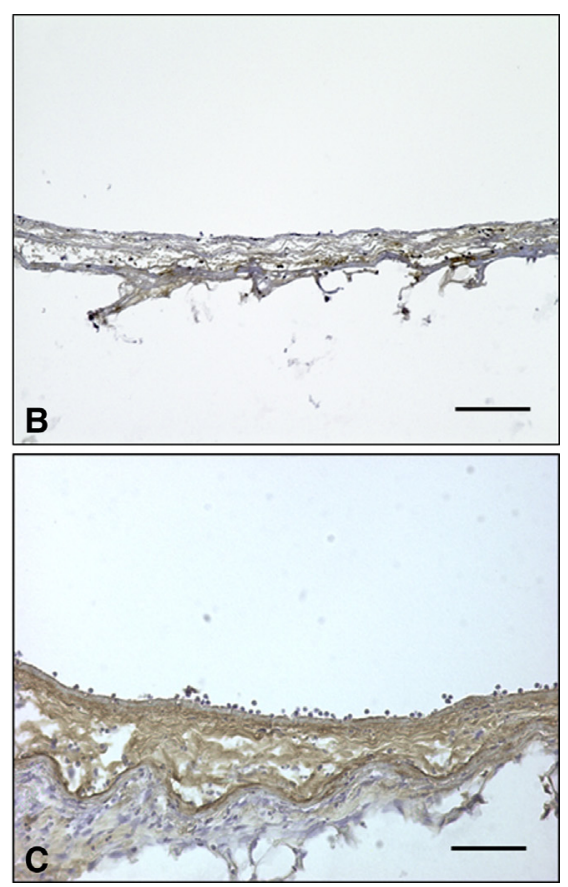

FIGURE 1. A, Schematic illustration of the electroporation device and representative photographs of green fluorescent protein immunostaining 3 days after implantation. B, Control and C, microRNA-145 (scale bar, $100 \mu \mathrm{m}$ ). Green fluorescent protein-positive cells were detected in the media of the microRNA145 -transduced grafts.

SuperMix for quantitative reverse transcriptase-PCR (Invitrogen, Carlsbad, Calif) in accordance with the manufacturer's instructions. Real-time PCR was performed on the StepOnePlus Real-Time PCR System (Applied Biosystems, Oakville, Ontario, Canada) using the SybrGreen quantitative PCR Mastermix (Qiagen). Custom-designed primers for rabbit serum response factor ([SRF] 5'-CCACGGACCAGAGAATGAGT-3 $3^{\prime}$ and $5^{\prime}$ GGCTTCAGTGTGTCCTTGGT- ${ }^{\prime}$ ) and myocardin (5'-GCATCACGGATGGATTCTCT- $3^{\prime}$ and $5^{\prime}$-ACTGCAGCCCATTACTGTCC- $3^{\prime}$ ) were purchased from Life Technologies Japan, Ltd (Tokyo, Japan). The gene expression data were analyzed using the relative standard curve method. The expression level of mRNA was divided by the mRNA level of the housekeeping gene glyceraldehyde-3-phosphate dehydrogenase.

\section{Statistical Analysis}

All values are presented as the mean \pm standard error. The data were evaluated using an unpaired Student $t$ test using Statview software, version 5.0 (SAS Institute, Cary, NC).

\section{RESULTS \\ GFP Immunostaining}

At 3 days after implantation, several GFP-positive staining areas were detected in the media of the miR-145-transduced graft, indicating successful gene transduction of miR-145 into the bypass grafts using the electroporation method (Figure 1, $B$ and $C$ ).

\section{Intimal Hyperplasia}

As shown in Figure 2, $A$, in the arterialized vein grafts at 4 weeks postoperatively, the control grafts had formed a thick neointima. In contrast, the miR-145-transduced grafts showed much thinner neointimal lesions. The statistical analysis of the cross-section demonstrated that the intima/ media area ratio of the miR-145-transduced group was significantly lower than that of the control group ( 2 weeks, $0.31 \pm 0.06$ vs $1.25 \pm 0.18, P<.01, \mathrm{n}=6$; 4 weeks, $0.22 \pm$ 0.04 vs $1.13 \pm 0.23, P<.01, \mathrm{n}=8$; Figure $2, B$ ).

Figure 2, $C$, shows the comparison of the neointimal lesion thickness at 2 and 4 weeks after implantation in each group. The intimal thickness was significantly lower in the miR-145-transduced group at both 2 and 4 weeks after implantation ( 2 weeks, $52.1 \pm 15.7$ vs $113.2 \pm 26.9 \mu \mathrm{m}$, $P<.05, \mathrm{n}=6$; 4 weeks, $42.4 \pm 4.8$ vs $136.5 \pm 38.3 \mu \mathrm{m}$, $P<.05, \mathrm{n}=8$ ).

\section{Immunohistochemical Staining for SM-1 and -2}

At 2 weeks after implantation, smooth muscle marker SM-1 immunostaining was detected equally in both control and miR-145-transduced vein grafts. Staining for SM-2, a mature SMC marker, revealed that the SM-2-positive area was barely detectable in the neointima of the control grafts, but SM-2 was positive in the reduced neointimal lesion of the miR-145-transduced grafts (Figure 3).

\section{Immunohistochemical Staining for Ki-67}

Figure 4, $A$ and $B$, illustrates the Ki-67-positive cells in the neointimal lesion of the grafts 2 weeks after implantation. The frequency of Ki-67-positive cells was much greater in the control grafts. The Ki-67 index was significantly greater in the control group than in the miR-145-transduced group $(11.1 \pm 1.0$ vs $23.2 \pm 1.3, \mathrm{n}=2)$. 

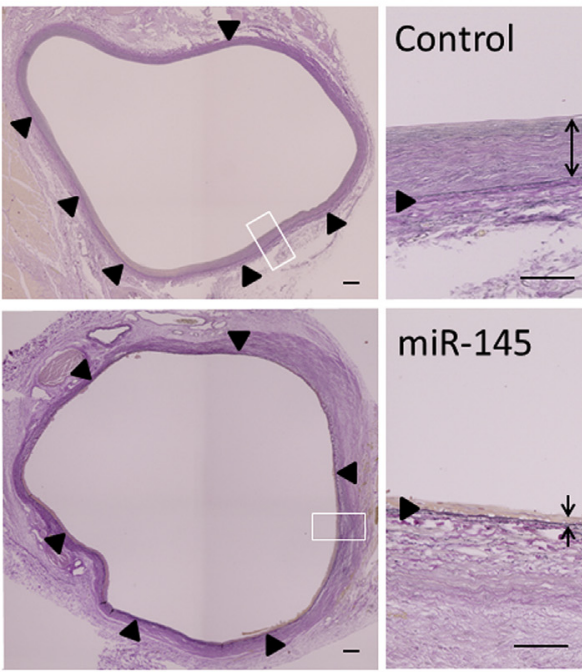

miR-145

A
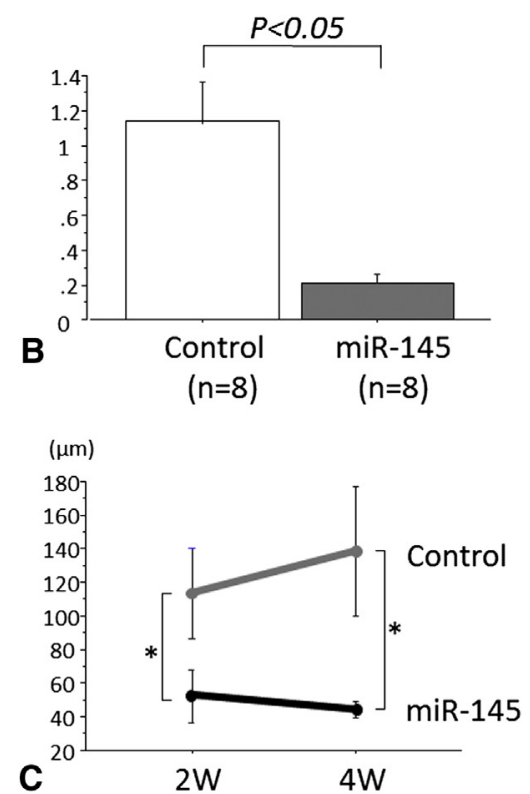

FIGURE 2. A, Representative photographs of vein grafts 4 weeks after implantation. Elastica van Gieson staining. Arrowheads indicate the internal elastic lamina (scale bar, $100 \mu \mathrm{m}$ ). B, Cross-sectional intima/media area ratio 4 weeks after implantation. C, Intimal thickness 2 and 4 weeks after implantation $(* P<.05)$. Neointimal lesion formation was significantly suppressed in the miR-145-transduced group 2 and 4 weeks after implantation. miR-145, microRNA-145.

\section{Quantitative Real-Time PCR for Myocardin and SRF}

The mRNA expression of myocardin was significantly upregulated in the miR-145-transduced grafts compared with the control grafts 3 days postoperatively $(2.03 \pm$ 0.99 vs $0.90 \pm 0.46, P<.001, \mathrm{n}=5$ ). In contrast, the mRNA expression level of SRF did not reach a statistically significant difference between the miR-145-transduced grafts and the control grafts 3 days postoperatively (Figure 5, $A$ and $B$ ).

\section{DISCUSSION}

The results of the present study have demonstrated that miR-145-transduced vein grafts inhibited neointimal lesion formation compared with the control grafts in the arterialized rabbit vein graft model. To our knowledge, this is the

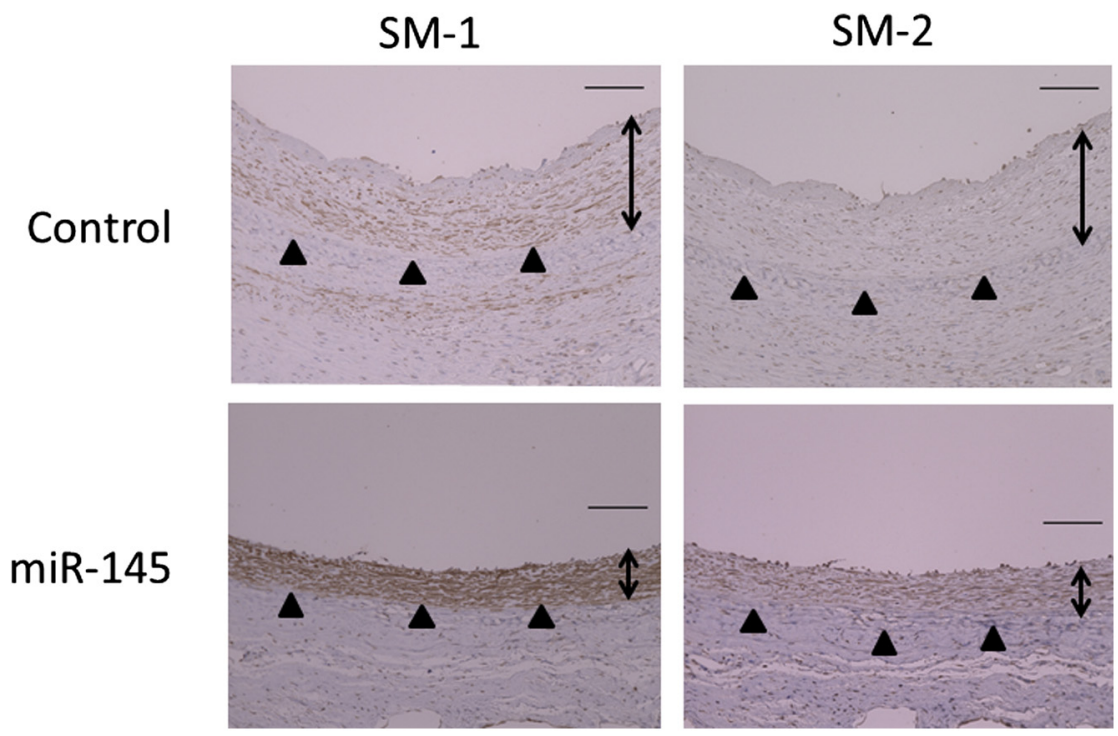

FIGURE 3. Smooth muscle (SM)-1 and SM-2 immunostaining of the vein grafts 2 weeks after implantation. Arrowheads indicate internal elastic lamina (scale bar, $100 \mu \mathrm{m}$ ). Staining for SM-2, a mature smooth muscle cell marker, revealed that the SM-2-positive area was barely detectable in the neointima of the control grafts, but SM-2 was positive in the reduced neointimal lesion of the microRNA-145-transduced grafts. 

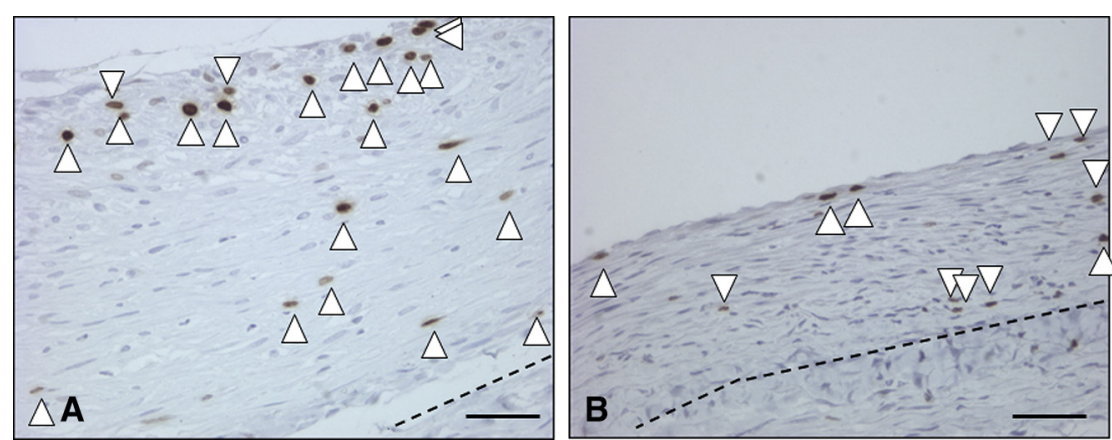

FIGURE 4. Ki-67 immunostaining of the vein grafts 2 weeks after implantation. A, Control. B, microRNA-145. White arrowheads indicate Ki-67-positive cells; dashed line, internal elastic lamina (scale bar, $50 \mu \mathrm{m}$ ). The frequency of Ki-67-positive cells was much greater in the control grafts, suggesting more proliferative cells were present in the control group.

first report on the introduction of miR-145, which specifically regulates the SMC phenotype, to vein graft disease in rabbit using a nonviral gene transfer method.

Previously, Cordes and colleagues ${ }^{5}$ had demonstrated the ability of miR-145 to efficiently direct the differentiation of vascular SMCs using transgenic mice experiments. They showed that miR-145 promotes the differentiation and represses the proliferation of SMCs. ${ }^{5}$ Our present study was based on their hypothesis that the restoration of miR-145 possibly suppresses the smooth muscle hyperplasia observed with vascular injury and atherosclerosis.

Cheng and colleagues ${ }^{4}$ revealed in their in vitro and in vivo studies that miR-145 was a vascular SMC phenotypic modulator that controlled the formation of vascular neointimal lesions. They demonstrated that, using balloon-injured rat arteries, the differentiation of vascular SMCs was accelerated by an adenovirus vector expressing miR-145. ${ }^{4}$

We recently revealed the essential function of miR-145 in the differentiation process of SMCs from undifferentiated human embryonic stem cells. Overexpression of miR-145 in the embryonic stem cell-derived precursor of SMCs
(ES-pre-SMCs) accelerated SMC differentiation, which was confirmed by analysis of smooth muscle marker expression, morphologic changes, and contractile function. ${ }^{7}$ From these findings, we believe that miR-145 works as an essential regulator for SMC differentiation.

Although various protein-based signaling cascades have been implicated in controlling the SMC phenotype, ${ }^{11,12,19}$ applying microRNA to vascular SMCs shows great potential owing to the manner in which it functions. The key characteristic of microRNA is its ability to regulate the expression of multiple genes, because it can bind to a number of mRNA targets. ${ }^{13}$ Cordes and colleagues ${ }^{5}$ revealed that miR-145 targeted a network of smooth muscle-related transcription factors, including Kruppellike factor 4, myocardin, and Elk-1 (a member of the ETS oncogene family), which can promote the differentiation and repress the proliferation of SMCs.

Among these factors, myocardin is a cardiac and smooth muscle-specific factor for SMC differentiation that was discovered by Wang and colleagues. ${ }^{20}$ They subsequently recognized that myocardin was a master regulator of
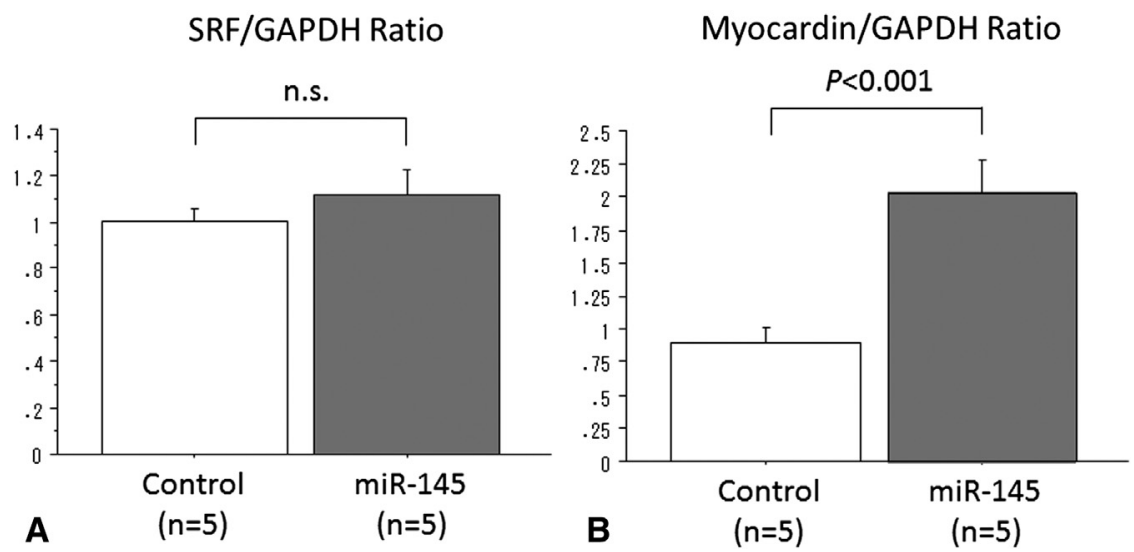

FIGURE 5. A, Serum response factor and B, myocardin mRNA expression in explanted grafts were evaluated by quantitative reverse transcriptasepolymerase chain reaction 3 days postoperatively. The mRNA expression level of myocardin was significantly upregulated in the microRNA-145-transduced grafts $(2.03 \pm 0.99$ vs $0.90 \pm 0.46, P<.001, \mathrm{n}=5)$. 
SMC differentiation. ${ }^{21}$ It is a potent coactivator for SRF and is also a component of a molecular switch for the SMCs' fate, which is sufficient for it to affect both the structural and the physiologic attributes of this cell type. SRF weakly activated the miR-143/145 enhancer upstream of a luciferase reporter but co-transfection of myocardin synergistically and robustly activated luciferase activity.

From these findings, although numerous factors and cofactors are concerned with SMC differentiation, we believe miR-145 has additive and synergic effects on its downstream factors for differentiation.

To date, many investigators have presented the results of procedures that inhibit vein graft disease in animal models. ${ }^{11,12,19,22-24}$ Nevertheless, none of these methods can be applied to clinical research or usage, because they use virus-mediated gene transduction. For example, the use of adenoviral vectors is one of the most popular methods in virus-mediated gene transfer. Its procedures have been already established, and its efficacy of gene transduction has been considered satisfactory. ${ }^{11,12,19,23,24}$ However, ethical issues and cytotoxicity remain owing to difficulties in virus handling and regulation. We recently documented the 3 goals that need to be achieved for clinical usage in gene therapy: suitable vectors, suitable genes, and an appropriate delivery system. ${ }^{25}$ In the present study, we chose the electroporation method to overcome virus-related problems and establish an appropriate delivery system for clinical application. Eefting and colleagues ${ }^{15}$ also chose electroporation-mediated gene transfer in their mouse arterial bypass model, resulting in the effective in vivo suppression of vein graft disease. However, the efficacy of gene transduction using the electroporation method is controversial. In addition, electroporation is not without its disadvantages, with heat injury being the most common problem. Previously, Matsumoto and colleagues ${ }^{18}$ established the optimal settings of in vivo gene transfer to the rabbit carotid artery using an electric pulse. They found that transgene expression was increased in nearly a voltagedependent manner $\leq 20 \mathrm{~V}$; however, administration at $>30$ $\mathrm{V}$ resulted in a marked decrease of cells in the arterial wall owing to apoptosis induced by electroporation. ${ }^{18}$ Similarly, we observed vacuolar degeneration and the disappearance of nuclei in the vasculature after high-energy delivery to the vein grafts (Appendix Table 2 and Appendix Figure 3). Thereafter, Yamaoka and colleagues ${ }^{16}$ established the optimal parameters for gene transfer into the rabbit vein graft model (pulse-on time, $5 \mathrm{~ms}$; interval time, 95 $\mathrm{ms}$; number of pulses, 10; voltage, $10 \mathrm{~V}$ [from the inner lumen side] and $30 \mathrm{~V}$ [from the adventitia side]). On the basis of their method, we modified these parameters in our experiments. Our electroporation device has mainly 2 characteristics: "poring pulse" and "transfer pulse." The former is for creating temporary pores (small holes) in the cell membranes with minimal damage and the latter for delivering the target molecules into cells with minimal damage. On the basis of the established optimal settings of electroporation ${ }^{16-18}$ and taking both our histologic findings and the distinguishing characteristics of the electric device into account, we adapted the former documented duration $(5 \mathrm{~ms})$ and interval time $(95 \mathrm{~ms})$ using a decrease in the number of poring pulses and an increase in the number of transfer pulses. Thus, we were able to achieve the successful gene transduction of miR145 (Figure 1, C).

SMC proliferation and migration into the intima are the key mechanisms in the pathogenesis of atherosclerosis and vein graft disease after surgical revascularization. Nagai and colleagues ${ }^{8}$ have demonstrated that smooth muscle myosin heavy chain isoforms are useful markers for vascular SMC differentiation. In the present study, many more SM-2-positive mature SMCs were present in the miR-145-transduced grafts than in the control grafts, indicating that the dedifferentiation of SMCs was inhibited. Because Ki-67-positive cells were observed more frequently in the control grafts than in the miR-145transduced grafts, it was determined that the neointima of the control grafts contained a significant number of proliferative cells. From these observations, we speculated that these cells originated from a synthetic phenotype of SMCs because the control grafts did not contain mature SM-2-positive cells. We, therefore, believe that proliferation of the synthetic phenotype was inhibited in the miR-145-transduced grafts compared with that in the control grafts. This is consistent with the theory from Elia and colleagues, ${ }^{6}$ who asserted that miR-145 gene expression functioned as a brake to dedifferentiation rather than as a stimulus for differentiation.

The precise mechanisms of the function of miR-145 should be clarified, and additional investigation is needed. We believe that downstream factors such as Kruppel-like factor 4 and Elk-1 would be good candidates for future study.

\section{CONCLUSIONS}

The results of our present study have demonstrated that nonviral transduction of miR-145, which specifically regulates the SMC phenotype, into the bypass graft inhibits neointimal lesion formation and could be a novel option to prevent vein graft disease after surgical revascularization.

We would like to thank Dr Tsuruyama, Department of Diagnostic Pathology, Kyoto University Graduate School of Medicine, for histologic diagnostic support and Ms Kataoka, Department of Cardiovascular Surgery, Kyoto University Graduate School of Medicine, for technical support.

\section{References}

1. Favarolo RG. Saphenous vein graft in the surgical treatment of coronary artery disease: operative technique. J Thorac Cardiovasc Surg. 1969;58:178-85. 
2. Dimitrova KR, Hoffman DM, Geller CM, Ko W, Lucido DJ, Dincheva GR, et al. Radial artery grafting in women improves 15 -year survival. J Thorac Cardiovasc Surg. 2013;146:1467-73.

3. Chamley-Campbell J, Campbell GR, Ross R. The smooth muscle cell in culture. Physiol Rev. 1979;59:1-61.

4. Cheng Y, Liu X, Yang J, Lin Y, Xu D, Lu Q, et al. MicroRNA-145, a novel smooth muscle cell phenotypic marker and modulator, controls vascular neointimal lesion formation. Circ Res. 2009;105:158-66.

5. Cordes KR, Sheehy NT, White MP, Berry EC, Morton SU, Muth AN, et al. miR145 and miR-143 regulate smooth muscle cell fate and plasticity. Nature. 2009; 460:705-11.

6. Elia L, Quintavalle M, Zhang J, Contu R, Cossu L, Latronico MV, et al. The knockout of miR-143 and -145 alters smooth muscle cell maintenance and vascular homeostasis in mice: correlates with human disease. Cell Death Differen. 2009; 16:1590-8.

7. Yamaguchi S, Yamahara K, Homma K, Suzuki S, Fujii S, Morizane R, et al. The role of microRNA-145 in human embryonic stem cell differentiation into vascular cells. Atherosclerosis. 2011;219:468-74.

8. Nagai R, Kuro-o M, Babij P, Periasamy M. Identification of two types of smooth muscle myosin heavy chain isoforms by cDNA cloning and immunoblot analysis. J Biol Chem. 1989;264:9734-7.

9. Aikawa M, Nalla SP, Kuro-o M, Kimura K, Nakahara K, Takewaki S, et al. Human smooth muscle myosin heavy chain isoforms as molecular markers for vascular development and atherosclerosis. Circ Res. 1993;73:1000-12.

10. Ishida M, Komori K, Yonemitsu Y, Taguchi K, Onohara T, Sugimachi K. Immunohistochemical phenotypic alterations of rabbit autologous vein grafts implanted under arterial circulation with or without poor distal runoffimplications of vein graft remodeling. Atherosclerosis. 2001;154:345-54.

11. Ohno N, Itoh H, Ikeda T, Ueyama K, Yamahara K, Doi K, et al. Accelerated reendothelialization with suppressed thrombogenic property and neointimal hyperplasia of rabbit jugular vein grafts by adenovirus-mediated gene transfer of C-type natriuretic peptide. Circulation. 2002;105:1623-6.

12. Doi K, Ikeda T, Itoh H, Ueyama K, Hosoda K, Ogawa Y, et al. C-type natriuretic peptide induces redifferentiation of vascular smooth muscle cells with accelerated reendothelialization. Arterioscler Thromb Vasc Biol. 2001;21:930-6.

13. Chen K, Rajewsky N. The evolution of gene regulation by transcription factors and microRNAs. Nat Rev Genet. 2007;8:93-103.
14. Frost RJ, van Rooij E. miRNAs as therapeutic targets in ischemic heart disease J Cardiovasc Transl Res. 2010;3:8280-9.

15. Eefting D, de Vries MR, Grimbergen JM, Karper JC, van Bockel JH, Quax PHA In vivo suppression of vein graft disease by nonviral, electroporation-mediated, gene transfer of tissue inhibitor of metalloproteinase-1 linked to the amino terminal fragment of urokinase (TIMP-1.ATF), a cell-surface directed matrix metalloproteinase inhibitor. J Vasc Surg. 2010;51:429-37.

16. Yamaoka T, Yonemitsu Y, Komori K, Baba H, Matsumoto T, Onohara T, et al. Ex vivo electroporation as a potent new strategy for nonviral gene transfer into autologous vein grafts. Am J Physiol Heart Circ Physiol. 2005;289:1865-72.

17. Csiszar A, Smith K, Labinskyy N, Orosz Z, Rivera A, Ungvari Z. Resveratorol attenuates TNF- $\alpha$-induced activation of coronary arterial endothelial cells: role of NF- $\kappa$ B inhibition. Am J Physiol Heart Circ Physiol. 2006;291:1694-9.

18. Matsumoto K, Komori K, Shoji T, Kuma S, Kume M, Yamaoka T, et al. Successful and optimized in vivo gene transfer to rabbit carotid artery mediated by electronic pulse. Gene Ther. 2001;8:1174-9.

19. Ikeda T, Itoh H, Komatsu Y, Hanyu M, Yoshimasa T, Matsuda K, et al. Natriuretic peptide receptors in human artery and vein and rabbit vein graft. Hypertension. 1996;27:833-7.

20. Wang D, Chang PS, Wang Z, Sutherland L, Richardson JM, Small E, et al. Activation of cardiac gene expression by myocardin, a transcriptional cofactor for serum response factor. Cell. 2001;105:851-62.

21. Wang Z, Wang D, Pipes GCT, Olson EN. Myocardin is a master regulator of smooth muscle gene expression. Proc Natl Acad Sci USA. 2003;100: 7129-34.

22. Chen Z, Hasegawa T, Tanaka A, Okita Y, Okada K. Pioglitazone preserves vein graft integrity in a rat aortic interposition model. J Thorac Cardiovasc Surg. 2010;140:408-16.

23. Kallenbach K, Salcher R, Heim A, Karck M, Mignatti P, Haverich A. Inhibition of smooth muscle cell migration and neointima formation in vein grafts by overexpression of matrix metalloproteinase-3. J Vasc Surg. 2009;49:750-8.

24. Petrofski JA, Hata JA, Gehrig TR, Hanish SI, Williams ML, Thompson RB, et al. Gene delivery to aortocoronary saphenous vein grafts in a large animal model of intimal hyperplasia. J Thorac Cardiovasc Surg. 2004;127:27-33.

25. Masumoto H, Sakata R. Cardiovascular surgery for realization of regenerative medicine. Gen Thorac Cardiovasc Surg. 2012;60:744-55. 


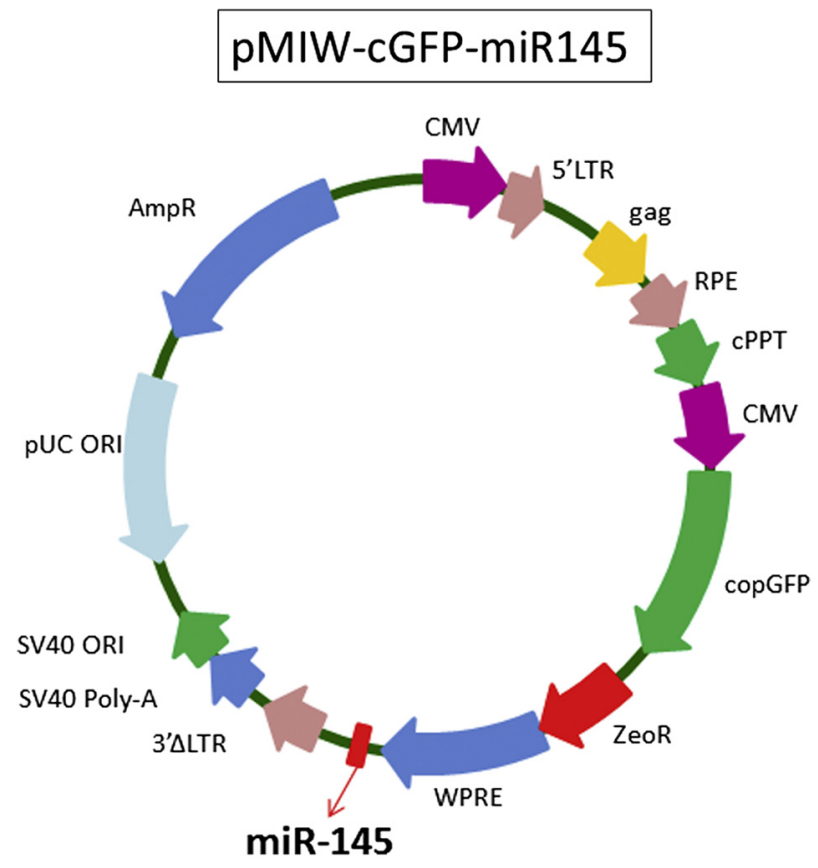

APPENDIX FIGURE 1. Schema of the construct of the microRNA-145 (miRNA-145) expression vector, which included microRNA-145 and a green fluorescent protein expression site.

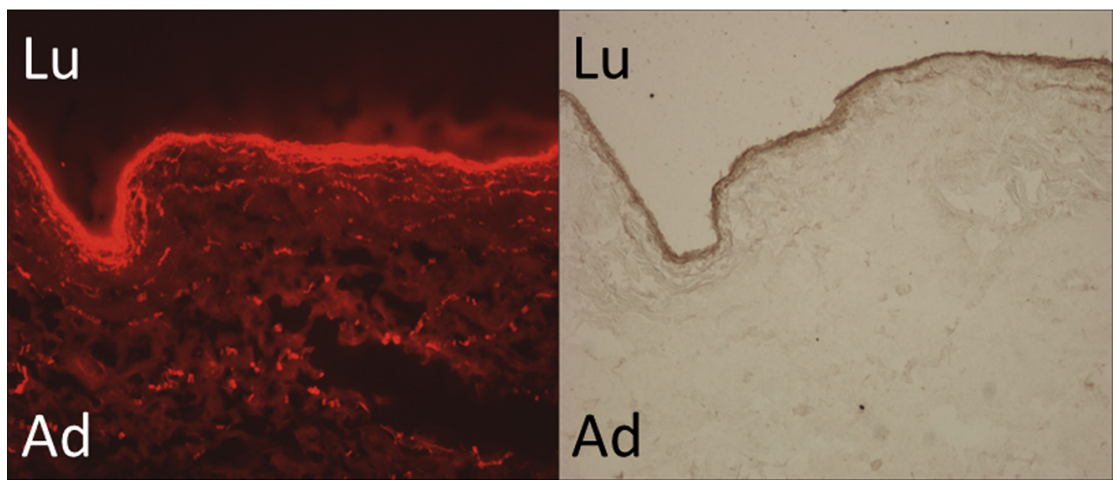

APPENDIX FIGURE 2. Left, DsRed fluorescent image and Right, DsRed immunostaining 2 days after electroporation (original magnification $\times 200$ ). $L u$, Lumen side; $A d$, adventitia side. Apparent DsRed expression in the lumen side was observed, indicating successful gene transduction after adopting the electric parameters of sample 4 (Appendix Table 1). 

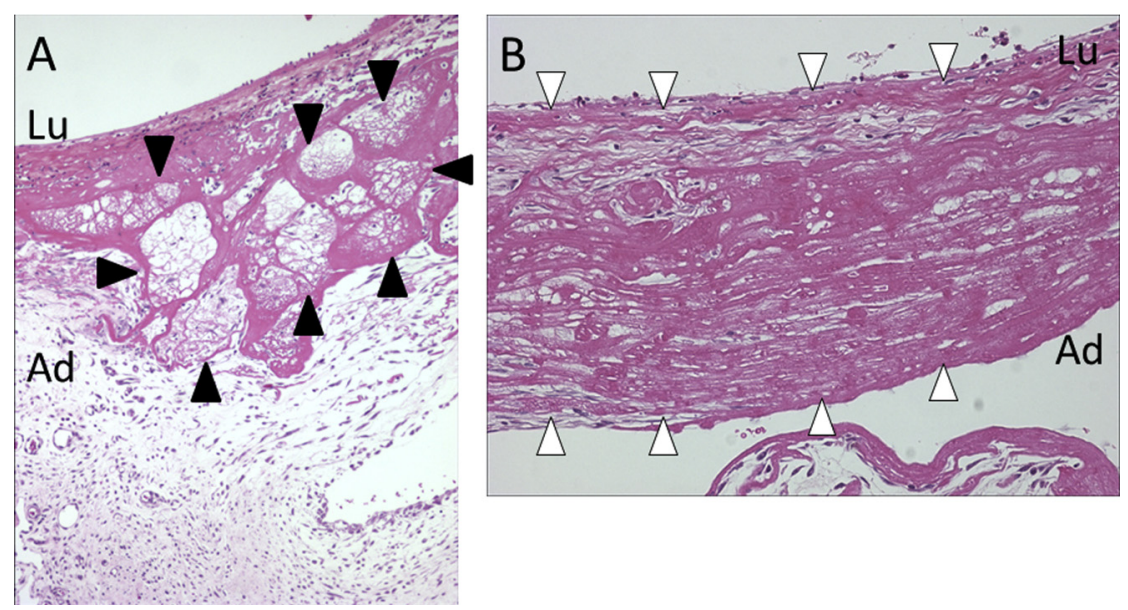

APPENDIX FIGURE 3. Representative photographs of degenerative vasculature in the preliminary in vivo study using a microRNA-145 expression vector. Electric parameters are described in Appendix Table 2. The vein grafts were explanted 2 weeks after implantation (hematoxylin and eosin staining). $L u$, Lumen side; $A d$, adventitia side. A, Black arrowheads indicate the vacuolar degeneration in the vasculature (original magnification $\times 100$ ). B, Between white arrowheads, the disappearance of nuclei was observed in almost all layers of the vasculature (original magnification $\times 200$ ).

APPENDIX TABLE 1. Four examples of $>\mathbf{2 0}$ settings of 4 electric parameters in a preliminary in vitro study using a DsRed expression vector

\begin{tabular}{|c|c|c|c|c|c|c|c|c|c|c|c|}
\hline & \multicolumn{5}{|c|}{ "Poring pulse" } & \multicolumn{5}{|c|}{ "Transfer pulse" } & \multirow[b]{2}{*}{$\begin{array}{c}\text { Total } \\
\text { energy }(J)\end{array}$} \\
\hline & Vol $(\mathbf{V})$ & Dur (ms) & Int (ms) & Freq (n) & $\begin{array}{r}\text { Delivered } \\
\text { energy }(\mathbf{J})\end{array}$ & Vol $(\mathbf{V})$ & Dur (ms) & Int (ms) & Freq (n) & $\begin{array}{r}\text { Delivered } \\
\text { energy }(\mathbf{J})\end{array}$ & \\
\hline Control & - & - & - & - & - & - & - & - & - & - & - \\
\hline Sample 1 & 25 & 5 & 50 & 2 & 0.306 & 10 & 5 & 95 & 10 & 0.034 & 0.340 \\
\hline Sample 2 & & & & 4 & 0.425 & & 5 & 95 & 10 & 0.036 & 0.461 \\
\hline Sample 3 & & & & 4 & 0.478 & & 10 & 90 & 10 & 0.066 & 0.544 \\
\hline Sample 4 & & & & 6 & 0.626 & & 10 & 90 & 5 & 0.070 & 0.695 \\
\hline
\end{tabular}

Vol, Voltage; Dur, pulse duration; Int, interval time; Freq, number of pulses.

APPENDIX TABLE 2. Electric parameters in a preliminary in vivo study using a microRNA-145 expression vector based on the in vitro study using a DsRed expression vector

\begin{tabular}{|c|c|c|c|c|c|c|c|c|c|c|c|}
\hline & \multicolumn{5}{|c|}{ "Poring pulse" } & \multicolumn{5}{|c|}{ "Transfer pulse" } & \multirow[b]{2}{*}{$\begin{array}{c}\text { Total } \\
\text { energy }(\mathbf{J}) \\
\end{array}$} \\
\hline & Vol (V) & Dur (ms) & Int (ms) & Freq (n) & $\begin{array}{l}\text { Delivered } \\
\text { energy }(J)\end{array}$ & Vol (V) & Dur (ms) & Int (ms) & Freq (n) & $\begin{array}{l}\text { Delivered } \\
\text { energy }(J)\end{array}$ & \\
\hline miR-145 & 25 & 5 & 50 & 6 & 0.832 & 10 & 10 & 90 & 5 & 0.090 & 0.922 \\
\hline
\end{tabular}

Vol, Voltage; Dur, pulse duration; Int, interval time; Freq, number of pulses. 